\title{
Comprehensive Application of the Theory of Fuzzy Logic and Neural Networks to Predict the Demand for Drugs
}

\section{Ramiz Alekperov*}

Professor, Department of Computer Engineering, Odlar Yurdu University, Baku, Azerbaijan

*Corresponding Author: Ramiz Alekperov, Professor, Department of Computer Engineering, Odlar Yurdu University, Baku, Azerbaijan.

E-mail: ramizalekper@gmail.com, ORCID ID: 0000-0001-6001-5384
Received: April 26, 2021

Published: May 15, 2021

(C) All rights are reserved by Ramiz Alekperov.

\begin{abstract}
Determining the need for medicines and medical supplies is directly related to the characteristics of their products, their actual consumption, and the identification of patterns of changes in demand for them. This article discusses the use of fuzzy logic and a neural network to predict the demand for pharmaceutical products in a distributed network, in conditions of insufficient information, a large assortment, and the influence of risk factors. A comprehensive approach to solving forecasting problems is proposed using: the theory of fuzzy logic - when forecasting emerging and unmet needs and a neural network - if there is a lot of retrospective information about the actual sale of drugs. A method for fuzzy classification of drug demand using ABC and XYZ analysis is described. Using this approach to solve the problems of forecasting demand allows you to get statistics and experience. The general algorithm, mathematical interpretation, and examples of forecasting the demand for pharmaceutical products in the face of uncertainty of information are given, and the general structure of the system for forecasting the demand for drugs is described. A fragment of the program code for predicting the demand for drugs based on neural networks for cases with sufficient sales statistics is presented.

Keywords: Demand Forecasting; Pharmaceutical Market; Fuzzy Classification; Neural Networks; ABC Analysis; XYZ Analysis, Crossanalysis
\end{abstract}

\section{Introduction}

The pharmaceutical market is an important area of the country's economy, which must be given special attention due to the fact that it is one of the necessary factors for the timely provision of human health. Today, there are a large number of pharmaceutical products (medicines and equipment), which are mass-market goods by terms, the use of which can be divided into durable goods (for example, sanitation, hygiene, medical devices) and short-term use (medicines, medicine plant materials, medical cosmetics) [1]. Along with this, there are pharmaceutical products, which, due to either high prices, or low-quality characteristics, or due to lack of information, turn into passive goods. Determining the need for medicines and drugs is directly related to their characteristics, their actual consumption, and the identification of patterns of change in demand for them.
The factors influencing the demand for pharmaceuticals differ from the factors of demand for the products traditionally offered to consumers. The definition of demand is associated with the establishment of the actual consumption of medicines, the identification of patterns of demand, taking into account the dynamics and a whole range of quantitative and qualitative factors affecting their consumption. And on the other hand, not every need can be quantified and can be satisfied with the market.

In this regard, the main task of studying the situation in the sale of medicines is to determine to what extent the state of their sale corresponds to demand, how to change these indicators in the near future, and what methods should be used for forecasting in order to satisfy the smooth supply of medicines and drugs to the population and the pharmacy network. 
As you know, the demand is divided into realized (satisfied - the actual sale of medicines with sufficient and constant availability in the pharmacy network), unsatisfied (medicines that are supplied to the pharmacy network in insufficient quantities or unevenly) and the emerging demand - clearly expressed demand for medicines, which, as a rule, include new and little-known types of pharmaceutical products.On the other hand, demand can be divided into classes: actual implementation with a good degree of satisfaction (there are at least 10 times the facts of satisfaction), with a small amount of satisfaction (the amount of satisfaction or sale is in the range of $[0 \div 10])$.

\section{Methodology}

Demand forecasting method

Currently, there are a large number of forecasting methods [2]: formal methods, expert forecasting, adaptive methods, etc. Studies have shown that at present there is no universal forecasting method that allows obtaining a forecast system for drug demand with sufficient accuracy for practical purposes. In each case, it is necessary to choose the appropriate forecasting methods, focusing on the availability of reliable information. On the other hand, with insufficient information about demand satisfaction or a small amount of retrospective, factual data, for example, in cases of emerging or unsatisfied demand, managers usually use their experience and intuition and use unclearly formulated requirements, which leads to the use of an approach using soft computing technology [5].

We propose a comprehensive approach to solving the problem of forecasting using [5,6,13]: 1 . the theory of fuzzy logic in predicting emerging and unmet demand and 2 . the neural network in the presence of a large amount of retrospective information on the actual sale of drugs. The general algorithm for predicting the demand for drugs is given below (Figure 1):

- $\quad$ Step 1: Collection (taking into account the seasonality factor), filtering information on the sale of drugs, and normalizing statistics. 2. Formation of interval dynamics between sales.

- $\quad$ Step 2: Classification of sales taking into account the facts of profitability and the coefficient of variation, which allows assessing the stability of sales.
- $\quad$ Step 3. If the drug belongs to a class for which there is not enough sales information, go to step 5.

- $\quad$ Step 4: The use of a neural network to predict the time series of drug sales. To take into account the seasonality factor, choose the appropriate neural network architecture for predicting the insurance stock for drugs over a certain period of time.

- $\quad$ Step 5: Applying fuzzy logic to determine the desired best quantity of demand for unmet and emerging demand. The base of fuzzy rules will be formed according to the experience, intuition of managers and taking into account the characteristics of medicines.

- $\quad$ Step 6: According to the results of forecasting and fuzzy logic, to form a demand for medicines for a certain period.

- $\quad$ Step 7: Calculate the total demand for medicines, taking into account the current balance of the drug in the warehouses of the pharmacy network.

The general structure of the system for forecasting the demand for drugs. The structure of the proposed system for forecasting the demand for drugs is described in figure 1, the general algorithm of which is described above. Each step of the general forecasting algorithm is implemented by the corresponding software module developed on the basis of the MATLAB computing environment. As can be seen from the figure 1, depending on the classification group, the choice of the demand forecasting method is carried out. For example, if the product belongs to the groups AZ, BZ and $\mathrm{CZ}$, then expert systems are used for forecasting. If there is a large amount of statistical data, neural networks are used, etc.

Fuzzy drugs demand classification using ABC and XYZ analysis

The main purpose of the classification of drugs is to understand how profitable and stable they are in demand and to determine the unprofitability of the goods sold and to give recommendations on choosing the forecasting method in step 2 of the algorithm for forecasting the demand for drugs that are described above. Typically, these tasks in practice are solved using special methods - ABC (ranks products by contribution to total sales, which allows you to determine the importance of products) and XYZ (how easy it is to sell products and how predictable they are) analyzes $[3,4]$. 


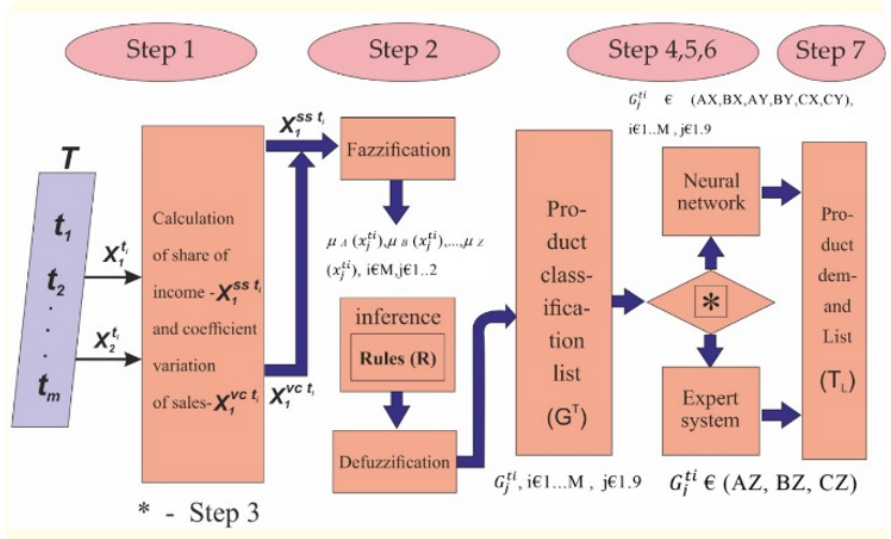

Figure 1: The structure of the proposed system for forecasting the demand for drugs.

Both methods of analysis are based on the Pareto principle and allow you to break down the weight of an assortment of goods into the following general classes:

- $\quad$ ABC analysis: a). A - the most important $(20 \%$ of the assortment $=80 \%$ of sales); in). B - intermediate (medium importance $(30 \%$ of the assortment $=15 \%$ of sales $) ; c)$. C - less important $(50 \%$ of the assortment $=5 \%$ of sales $)$.

- $\quad$ XYZ analysis: a). X - steady demand and high forecast accuracy, so their sales volume is easy to predict ( $010 \%)$; in). $Y$ is volatile demand (in particular, due to seasonality and stocks), but a forecast is possible. For more reliable results, additional analysis can be carried out (10-25\%); from). Z random demand, the forecast is impossible, since there are no patterns in consumption (from 25\%).

Combining both methods, you can get 9 classes of goods on the basis of which you can conduct a cross-analysis (Table 1) and give recommendations on choosing the method of forecasting them.

Table 1 shows how important it is to correctly identify the goods belonging to the listed classes. Based on the clear interval values of the boundaries of $\mathrm{ABC}$ and XYZ classes based on Pareto principles, when moving between boundaries, you can incorrectly determine, for example, which class the product belongs to, for example, AX or $\mathrm{AY}, \mathrm{BX}$ or $\mathrm{BY}$, where it is recommended to predict and determine the insurance for classes AY and BY stock, and for classes AX and $\mathrm{BX}$ to conduct a forecast minus excess insurance stock.
In this regard, in this paper, a method for the classification of drugs using fuzzy logic is proposed. The foundations of the theory of fuzzy logic were developed by Zadeh L. [5]. The works of Aliyev R.A. [6] and other scientific researchers list the following basic algorithms for fuzzy inference: 1. Mamdani algorithm; -Tsukamoto algorithm; 2. Larsen algorithm; 3. Sugeno algorithm 4. Aliyev algorithms (ALI-1, ALI-2, ALI-3, ALI-4).

In our case, due to the fact that the classification problem is considered as a logical derivation.

\begin{tabular}{|c|c|c|c|}
\hline $\begin{array}{c}\text { Class } \\
\text { number }\end{array}$ & $\begin{array}{c}\text { Class } \\
\text { name }\end{array}$ & Class properties & $\begin{array}{l}\text { Recommendations for } \\
\text { choosing a forecasting } \\
\text { method }\end{array}$ \\
\hline 1 & $\mathrm{CZ}$ & $\begin{array}{l}\text { Low importance } \\
\text { of goods, irregu- } \\
\text { lar consumption, } \\
\text { low predict- } \\
\text { ability }\end{array}$ & $\begin{array}{c}\text { Insufficient information about } \\
\text { the sale - to forecast based on } \\
\text { the experience and intuition } \\
\text { of managers (fuzzy logical } \\
\text { conclusion) }\end{array}$ \\
\hline 2 & $\mathrm{CY}$ & $\begin{array}{l}\text { Low importance } \\
\text { of goods, season- } \\
\text { al fluctuations, } \\
\text { medium degree } \\
\text { of predictability }\end{array}$ & $\begin{array}{l}\text { The constant amount of orders } \\
\text { is to predict, based on the } \\
\text { neural network, with a delay } \\
\text { of } 3 \text { months (fuzzy inference), } \\
\text { safety stock with the possibil- } \\
\text { ity of the company }\end{array}$ \\
\hline 3 & CX & $\begin{array}{l}\text { Low importance } \\
\text { of goods, stable } \\
\text { consumption, } \\
\text { high predict- } \\
\text { ability }\end{array}$ & $\begin{array}{c}\text { A large amount of retrospec- } \\
\text { tive static data - to forecast } \\
\text { safety stock based on a neural } \\
\text { network }\end{array}$ \\
\hline 4 & $\mathrm{BZ}$ & $\begin{array}{l}\text { Medium impor- } \\
\text { tance of goods, } \\
\text { irregular con- } \\
\text { sumption, low } \\
\text { predictability }\end{array}$ & $\begin{array}{l}\text { Insufficiency of information } \\
\text { about the sale - to predict, } \\
\text { based on the experience and } \\
\text { intuition of managers (fuzzy } \\
\text { inference), safety stock }\end{array}$ \\
\hline 5 & BY & $\begin{array}{c}\text { The aver- } \\
\text { age degree of } \\
\text { importance of } \\
\text { goods, seasonal } \\
\text { fluctuations, the } \\
\text { average degree } \\
\text { of predictability }\end{array}$ & $\begin{array}{l}\text { Neural Network Needs to } \\
\text { Predict Safety Stock }\end{array}$ \\
\hline 6 & $\mathrm{BX}$ & $\begin{array}{l}\text { Medium impor- } \\
\text { tance of goods, } \\
\text { stable con- } \\
\text { sumption, high } \\
\text { predictability }\end{array}$ & $\begin{array}{l}\text { A large amount of retrospec- } \\
\text { tive static data - it is necessary } \\
\text { to forecast demand based on } \\
\text { a neural network and minus } \\
\text { excess safety stock }\end{array}$ \\
\hline
\end{tabular}




\begin{tabular}{|c|c|c|c|}
\hline 7 & AZ & $\begin{array}{c}\text { Very impor- } \\
\text { tant goods, } \\
\text { irregular con- } \\
\text { sumption, low } \\
\text { predictability }\end{array}$ & $\begin{array}{c}\text { Insufficiency of information } \\
\text { about the sale - to predict, } \\
\text { based on the experience and } \\
\text { intuition of managers (fuzzy } \\
\text { inference), safety stock }\end{array}$ \\
\hline 8 & AY & $\begin{array}{c}\text { Very impor- } \\
\text { tant products, } \\
\text { seasonal varia- } \\
\text { tions, medium } \\
\text { predictability }\end{array}$ & $\begin{array}{c}\text { Neural Network Needs to } \\
\text { Predict Safety Stock }\end{array}$ \\
\hline 9 & AX & $\begin{array}{c}\text { Very impor- } \\
\text { tant products, } \\
\text { stable con- } \\
\text { sumption, high } \\
\text { predictability }\end{array}$ & $\begin{array}{c}\text { A large amount of retrospec- } \\
\text { tive static data - it is neces- } \\
\text { sary to forecast demand } \\
\text { based on a neural network } \\
\text { and minus excess safety } \\
\text { stock }\end{array}$ \\
\hline
\end{tabular}

Table 1: Properties of fuzzy classes and recommendations for choosing a method for forecasting sales.

Problem for an object with a discrete output, and to solve this problem, we consider the Sugeno algorithm, a general algorithm that is described as follows [7]:

Suppose that there is $1 . T\left\{t_{1}, t_{2}, \ldots, t_{M}\right\}$, where ti $€ T$ is the set of medicines and preparations (marketable products) for which classification is carried out; 2 . set A - profitability-ordered goods (sales share), calculated as a percentage of total income, sorted in descending order and summed up by a cumulative total, which consists of fuzzy sets, for $A B C$ classification, respectively, $A_{1}(A), A_{2}(B)$, $A_{3}(C)$; 3 . the set $Z$ - ordered by the value of the coefficient of variation (cv) of sales, which shows the percentage deviation of sales from the average and consists of fuzzy sets, for the XYZ classification, respectively, $Z_{1}(X), Z_{2}(Y), Z_{3}(Z)$ and 4 . the set $G\{g 1, g 2, \ldots, g 9\}$, where $g_{i} € G$ is the set of combined classes described in table 1 . We assume that the lower the coefficient of variation, the greater the stability of the sales. The algorithm for $\mathrm{ABC}$ and $\mathrm{XYZ}$ analyzes is described in detail in papers, for example $[3,4]$.

Assume that $\mathrm{n}$ rules are used to solve the problem:

$$
\begin{aligned}
& \mathrm{R}_{1} \text { : if } \mathrm{x}_{1} \text { is } A_{1} \text { and } \mathrm{x}_{2} \text { is } Z_{1} \text { then } \mathrm{g} \text { is } \mathrm{g}_{1} \text {; } \\
& \mathrm{R}_{2} \text { : if } \mathrm{x}_{1} \text { is } A_{2} \text { and } \mathrm{x}_{2} \text { is } Z_{2} \text { then } \mathrm{g} \text { is } \mathrm{g}_{2} \text {; } \\
& \mathrm{R}_{\mathrm{n}} \text { : if } \mathrm{x}_{1} \text { is } A_{n} \text { and } \mathrm{x}_{2} \text { is } Z_{n} \text { then } \mathrm{g} \text { is } \mathrm{g}_{\mathrm{n}} \text {; }
\end{aligned}
$$

Where $i € 1 \ldots n$, where $n$ is the total number of fuzzy inference rules; $x$ and $y$ are the names of the input variables; $g$ is the name of the output variable; $A_{1}, A_{2} \ldots A_{n} ; B_{1}, B_{2} . . B_{n} ; g_{1}, g_{2} \ldots g_{n}$ are some given membership functions, and a clear knowledge of $g(0)$ must be determined on the basis of the information given and the clear values of $x_{1}(0), x_{2}(0)$.

The maximum number of rules depends on the number of terms of fuzzy linguistic variables that correspond to fuzzy sets A and Z.

We present the Sugeno algorithm for the general case where the number of rules is not known in advance.

We determine the degrees of truth for the premises of each rule $\left(\mathrm{R}_{\mathrm{i}}, \mathrm{i} € 1 . . \mathrm{n}\right)$ :

$$
\begin{aligned}
& \mathrm{R}_{1}:\left\{\mathrm{A}_{1}\left(\mathrm{x}_{1}(0)\right), \mathrm{Z}_{1}\left(\mathrm{x}_{2}(0)\right)\right\}, \\
& \mathrm{R}_{2}:\left\{\mathrm{A}_{2}\left(\mathrm{x}_{1}(0)\right), \mathrm{Z}_{2}\left(\mathrm{x}_{2}(0)\right)\right\}, \\
& \mathrm{R}_{\mathrm{n}}:\left\{\mathrm{A}_{\mathrm{n}}\left(\mathrm{x}_{1}(0)\right), \mathrm{Z}_{\mathrm{n}}\left(\mathrm{x}_{2}(0)\right)\right\}
\end{aligned}
$$

Applying the operation of the fuzzy logical minimum (in the formulas through “ $\wedge$ "), we find the "cut-off" levels for the premises of each of $R_{i}$, where $i € 1 \ldots n$.

$$
\begin{aligned}
& \mathrm{R}_{1}: \alpha_{1}=\mathrm{A}_{1}\left(\mathrm{x}_{1}(0)\right) \wedge \mathrm{Z}_{1}\left(\mathrm{x}_{2}(0),\right. \\
& \mathrm{R}_{2}: \alpha_{2}=\mathrm{A}_{2}\left(\mathrm{x}_{1}(0)\right) \wedge \mathrm{Z}_{2}\left(\mathrm{x}_{2}(0)\right) \\
& \mathrm{R}_{\mathrm{n}}: \alpha_{\mathrm{n}}=\mathrm{A}_{\mathrm{n}}\left(\mathrm{x}_{1}(0)\right) \wedge \mathrm{Z}_{\mathrm{n}}\left(\mathrm{x}_{2}(0)\right)
\end{aligned}
$$

We determine the individual outputs for each of $R_{i}$, where $i € 1 . . n$ :

$$
\begin{aligned}
& \mathrm{R}_{1}:=\mathrm{a}_{1} \mathrm{x}_{1}(0)+\mathrm{b}_{1} \mathrm{x}_{1}(0), \\
& \mathrm{R}_{2}:=\mathrm{a}_{2} \mathrm{x}_{1}(0)+\mathrm{b}_{2} \mathrm{x}_{2}(0), \\
& \mathrm{R}_{\mathrm{n}}:=\mathrm{a}_{\mathrm{n}} \mathrm{x}_{1}(0)+\mathrm{b}_{\mathrm{n}} \mathrm{x}_{2}(0) ;
\end{aligned}
$$

Determine the clear value of the output variable:

$$
\mathrm{g}_{0}=\sum_{i=1}^{n} \frac{\alpha \mathrm{i} * g_{i}^{*}}{\alpha \mathrm{i}}
$$

The structure of the developed fuzzy inference system based on the algorithm of the Sugeno system is shown in figure 1. As can 
be seen from the figure, the system of fuzzy inference for the classification of drugs includes two inputs: share of income and coefficient variation of sales determining the level of sales stability, as well as one way out - classification groups.

The following is a description of a fuzzy inference system for classifying drugs.

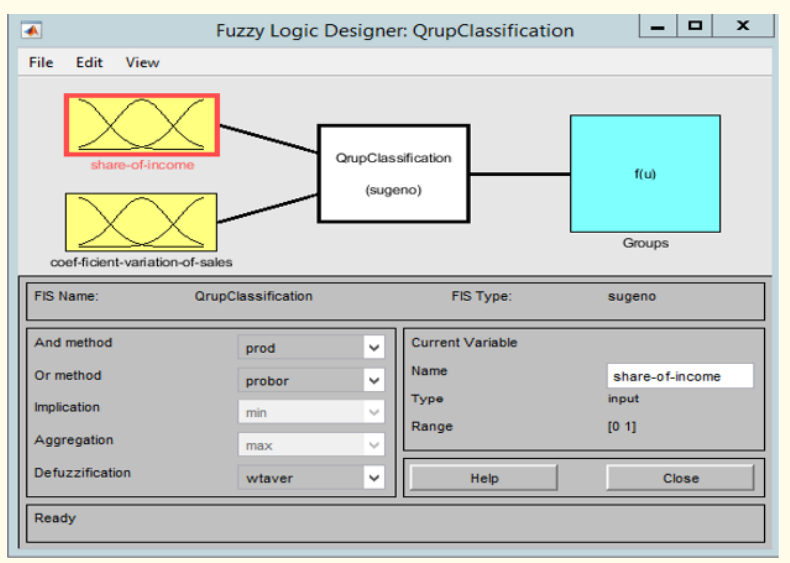

(a)

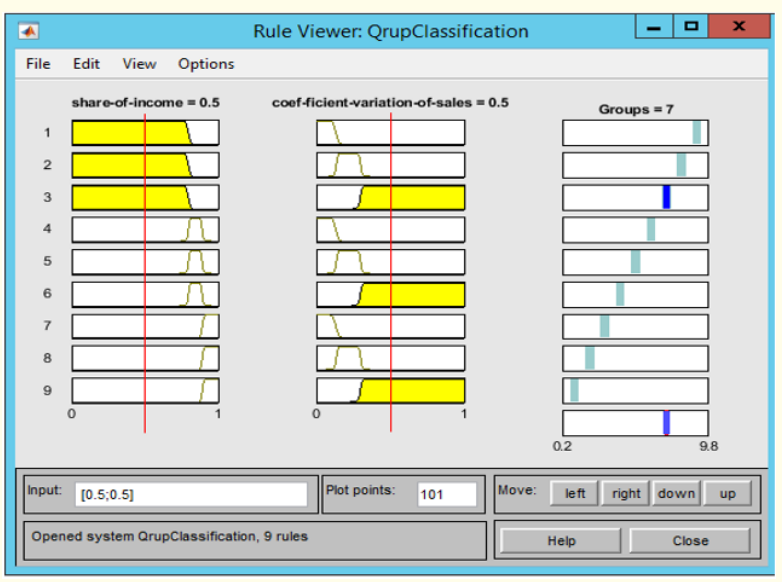

(b)

Figure 2: (a) The structure of the fuzzy inference system; (b) Graphic representation of rules.

\section{Definition of input variables}

As a linguistic variable for the input variable share of income (x1), three sets of fuzzy variables were chosen (Figure 3 (a)), having the following non-linear forms of membership functions $[5,6]$ :

- $\quad$ High profitability - zmf (Z-shaped membership function) with parameters [0.7685 0.8241]

- $\quad$ Average (Middle)) profitability - gbellmf (Generalized bellshaped membership function) with parameters [0.0467 5.46 0.8443]

- $\quad$ Low profitability - smf (S-shaped membership function) parameters [0.8717 0.9114]

- $\quad$ For the input variable x2 (sales stability - determined by the values of the coefficient of variation of sales), three sets of fuzzy variables were selected (Figure 3 (b)) having the following nonlinear types of membership function:

- High sales stability (corresponds to the concept - the coefficient of variation is low) - zmf with parameters [0.09656 0.167]

- $\quad$ Average (Middle) sales stability (corresponds to the concept - the coefficient of variation is average) - gbellmf with parameters [0.082 8.17 0.218];

- Low sales stability (consistent with the concept - the coefficient of variation is high) - sigmf (Sigmoidal membership function) with parameters [150 0.2976]

Note that the calculated values of these input parameters are in the range $x €[0 \ldots 100]$. Normalization of these indicators is carried out using the formula:

$x_{i}=\frac{x_{i}-x_{\min }}{x_{\max }-x_{\min }}$

Where $\mathrm{x}_{\min }, \mathrm{x}_{\max }-$ minimum and maximum values of the input parameter.

\section{Output variable}

The output variable Qroups has 9 linear expressions corresponding to discrete class values shown in table 1 ., respectively: 


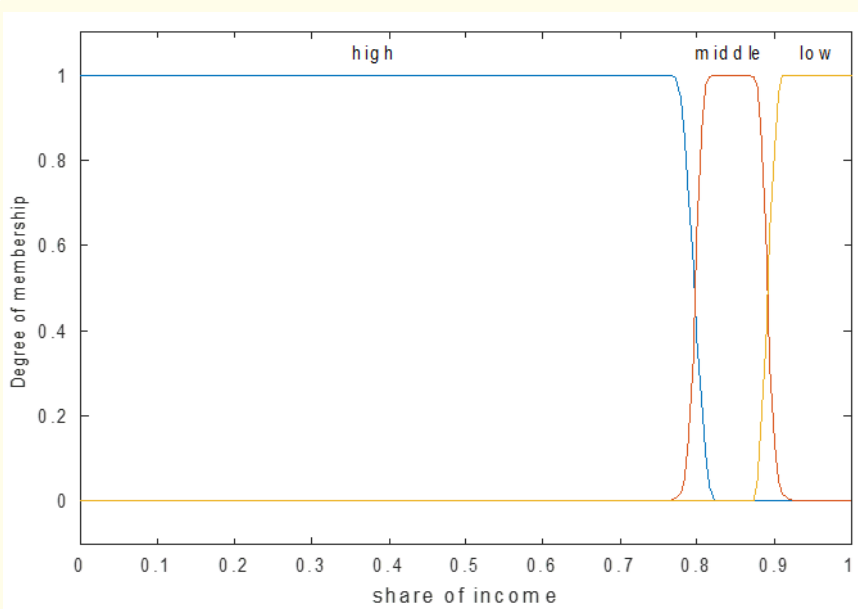

(a)

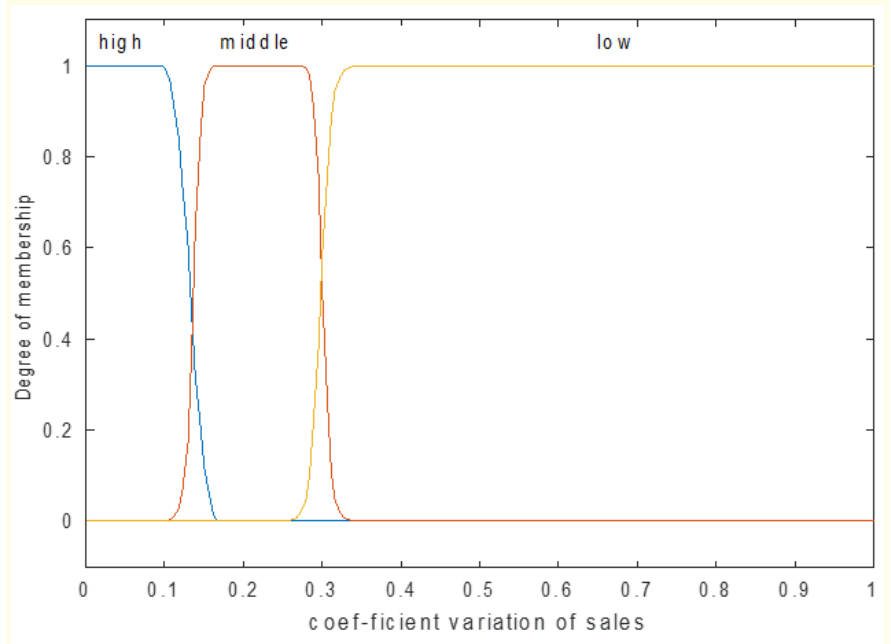

(b)

Figure 3: (a) The structure of the fuzzy inference system; (b) Graphic representation of rules.

1.Output = 9 - group 'AX'; 2.0utput = $8-$ group 'AY'; 3.0utput $=7$ - group 'AZ'; 4.0utput = 6 - group 'BX'; 5.0utput = 5 - group 'BY'; 6.0utput $=4$ - group 'BZ'; 7.0utput $=3-$ group 'CX'; 8. Output $=2$ group 'CY'; 9.0utput = 1 - group 'CZ'.

\section{Rules}

Nine rules have been created for linking input and output variables:
- If $\mathrm{x} 1$ (share of income) is high and $\mathrm{x} 2$ (sales stability) is high then $y$ (classification groups) is $9(\mathrm{AX})(\mathrm{CF}=1)$

- If $x 1$ (share of income) is high and $x 2$ (sales stability) is middle then $y$ (classification groups is $8(\mathrm{AY})(\mathrm{CF}=1)$

- If $\mathrm{x} 1$ (I share of income) is high and $\mathrm{x} 2$ (sales stability) is low then $y$ (classification groups) is $7(\mathrm{AZ})(\mathrm{CF}=1)$

- If ( $\mathrm{x} 1$ (share of income) is middle and $\mathrm{x} 2$ (sales stability) is high then $\mathrm{y}$ (classification groups) is $6(\mathrm{BX})(\mathrm{CF}=1)$

- If $x 1$ (share of income) is middle) and $\times 2$ (sales stability) is middle then $y$ (classification groups) is $5(\mathrm{BY})(\mathrm{CF}=1)$

- If $x 1$ (share of income) is middle and $x 2$ (sales stability) is low then $y$ (classification groups) is $4(\mathrm{BZ})(\mathrm{CF}=1)$

- If $\times 1$ (share of income) is low and $x 2$ (sales stability) is high then $y$ (classification groups) is $3(\mathrm{CX})(\mathrm{CF}=1)$

- If $x 1$ (share of income) is low and $x 2$ (sales stability) is middle then $y$ (classification groups) is $2(\mathrm{CY})(\mathrm{CF}=1)$

- If $\mathrm{x} 1$ (share of income) is low and $\mathrm{x} 2$ (sales stability) is low then $\mathrm{y}$ (classification groups) is $1(\mathrm{CZ})(\mathrm{CF}=1)$.

Analysis of the Results and Discussion

Evaluation of the effectiveness of the developed inference algorithm for the classification of drugs and preparations was carried out using the approximate data shown in table 2 and 3.

In table 4 the results of the fuzzy logical inference are given, where counseling classes are defined for each drug and product.

An analysis of the results shows the high efficiency of the proposed inference algorithm for the classification of drugs.

The following is a description of a fuzzy inference system for classifying drugs. These rules provide the choice of one of the output expressions, depending on the values of the input variables. A graphic image of the rules is shown in Fig. 3. A weighted average (weaver) [7] was used as a defuzzification method.

The resulting approximated surface of the inference system is shown in figure 4. Methods and approaches to forecasting demand for various classes of drugs. After determining the class in accordance with the recommendations presented in table 1 recommendations, you can choose a method for forecasting demand for each product individually. 
In conditions of sales stability, a large amount of retrospective static data, and uncertainty, it is mainly proposed to use a neural network solution as a forecasting method [5, 6, 8-13]. The forecasting problem is posed as the problem of approximating a number of dynamics, i.e. building a function by a finite set of points, by the number of sales of medicines taken by month.

The problems of approximating experimental data can be solved using the following types of artificial neural networks: a multilayer perceptron, networks with radially basis functions, probability networks, and generalized regression networks.

For simplicity of calculation and reliability of sales forecasting for products from classes such as AX, BX, CX, we propose using the Generalized Regression Neural Network (GRNN) [5,6].

The task of approximating a function for a neural network is formed as a task of controlled learning (training with a teacher).

\begin{tabular}{|c|c|c|c|}
\hline Drugs & Income & Share & Share of income \\
\hline Drug8 & 500 & $32.85 \%$ & 0.33 \\
\hline Drug6 & 360 & $23.65 \%$ & 0.57 \\
\hline Drug1 & 284 & $18.66 \%$ & 0.75 \\
\hline Drug2 & 154 & $10.12 \%$ & 0.85 \\
\hline Drug7 & 110 & $7.23 \%$ & 0.93 \\
\hline Drug5 & 70 & $4.60 \%$ & 0.97 \\
\hline Drug3 & 28 & $1.84 \%$ & 0.99 \\
\hline Drug4 & 16 & $1.05 \%$ & 1.00 \\
\hline
\end{tabular}

Table 2. The share of sales of goods.

\begin{tabular}{|c|c|c|c|c|c|c|}
\hline \multirow{2}{*}{ Drugs } & \multicolumn{5}{|c|}{ Sales } & $\begin{array}{c}\text { Coefficient vari- } \\
\text { ation of sales }\end{array}$ \\
\cline { 2 - 7 } & March & April & May & June & July & 0.05 \\
\hline Drug1 & 80 & 68 & 75 & 76 & 73 & 0.25 \\
\hline Drug2 & 36 & 37 & 28 & 40 & 18 & 0.16 \\
\hline Drug3 & 26 & 25 & 30 & 18 & 23 & 0.37 \\
\hline Drug4 & 20 & 10 & 15 & 7 & 21 & 0.38 \\
\hline Drug5 & 20 & 7 & 30 & 21 & 28 & 0.52 \\
\hline Drug6 & 27 & 32 & 12 & 10 & 10 & 0.39 \\
\hline Drug7 & 15 & 27 & 32 & 18 & 10 & 0.12 \\
\hline Drug8 & 18 & 19 & 22 & 25 & 21 & \\
\hline
\end{tabular}

Table 3: Coefficients of variation in sales.

\begin{tabular}{|c|c|c|c|c|}
\hline Drugs & $\begin{array}{c}\text { Share of } \\
\text { income }\end{array}$ & $\begin{array}{c}\text { Coefficient variation } \\
\text { of sales }\end{array}$ & Class & $\begin{array}{c}\text { Class } \\
\text { Name }\end{array}$ \\
\hline Drug1 & 0.75 & 0.05 & 9 & $\mathrm{AX}$ \\
\hline Drug2 & 0.85 & 0.25 & 5 & $\mathrm{BY}$ \\
\hline Drug3 & 0.99 & 0.16 & 2 & $\mathrm{CY}$ \\
\hline Drug4 & 1.00 & 0.37 & 1 & $\mathrm{CZ}$ \\
\hline Drug5 & 0.97 & 0.38 & 1 & $\mathrm{CZ}$ \\
\hline Drug6 & 0.57 & 0.52 & 7 & $\mathrm{AZ}$ \\
\hline Drug7 & 0.93 & 0.39 & 1 & $\mathrm{CZ}$ \\
\hline Drug8 & 0.33 & 0.12 & 9 & $\mathrm{AX}$ \\
\hline
\end{tabular}

Table 4: Results of the operation of the fuzzy inference algorithm.

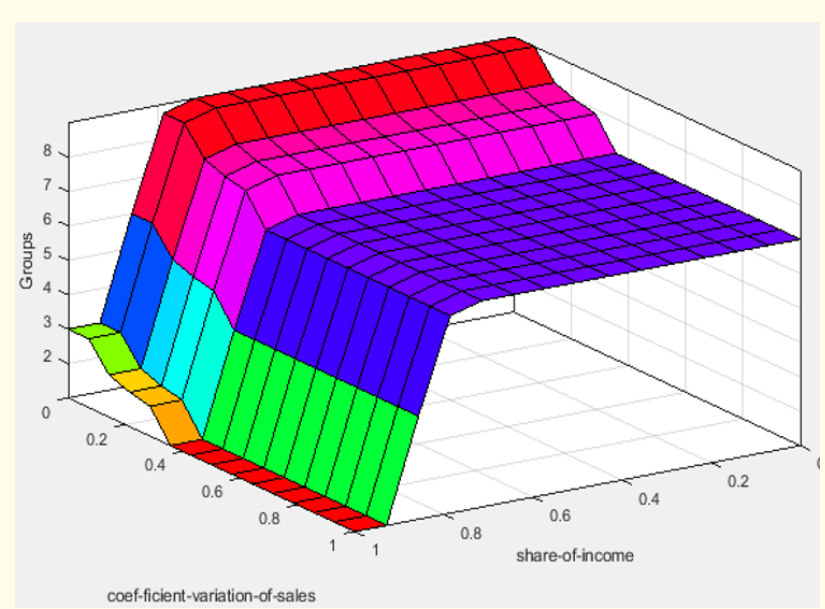

Figure 5: Approximate surface.

The essence of the problem is as follows. There are values of the function at individual points (nodes), a system of basis functions, and vectors of adjustable weight coefficients. It is necessary to train the network, i.e., to choose weights for the basic functions so that their combination gives a similar dependence that best approximates the set of values of the response function.

To create a GRNN neural network in MATLAB $[8,13]$, the newgrnn function was used. The function code written using the Neural Network Toolbox to approximate and forecast short-term sales is shown in figure 6.

The formed GRNN network uses only one input, two layers, one output, and 5 neurons in a hidden layer and successfully solves the 
problem of approximating and extrapolating a nonlinear dependence reconstructed from experimental points.

An analysis of the results shows the high efficiency of the proposed inference algorithm for the classification of drugs.

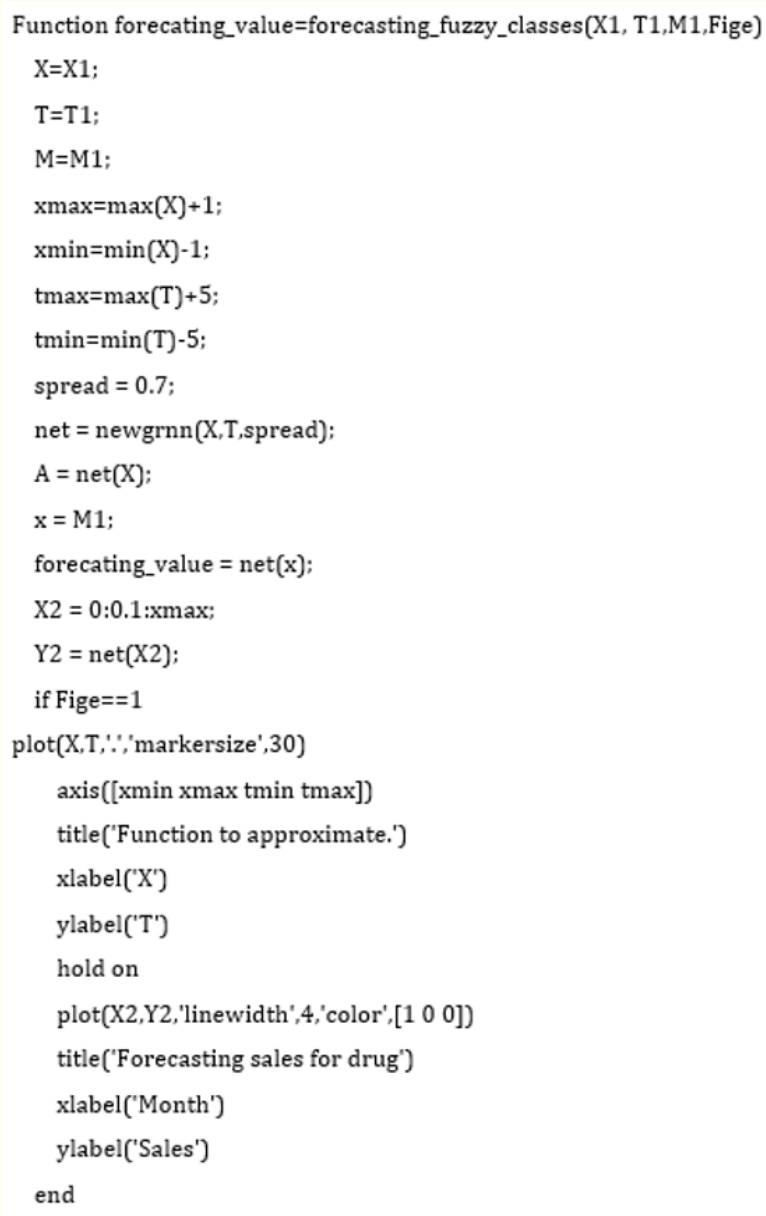

Figure 6: Short-term sales forecast function code.

Using this neural network for drugs Drug1 and Drug8, the following forecast values were obtained, respectively 73.0093 and 21.0124 , which indicates the stability of sales of goods from these classes.

For goods from the class AY, BY, CY which are characterized by quarterly, steady changes repeating from month to month in levels,

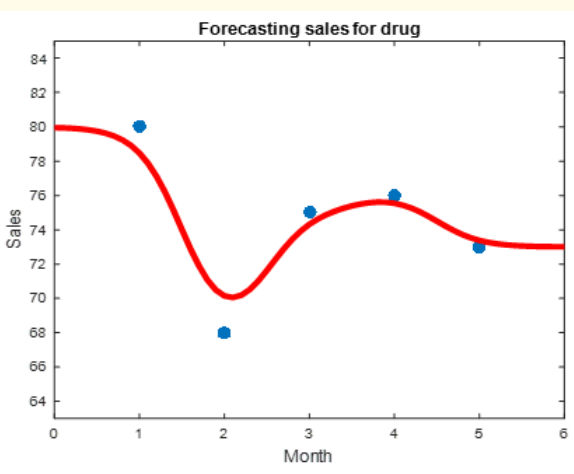

Figure 7: Graph with the results of training and forecasting for the 6 th month of the sale of the product Drug1.

i.e. seasonal variations, it is proposed to use a neural network with a delay at the entrance.

The lack of information and the small number of statistics on the sale determines the use of an expert system for making decisions on determining the demand for goods from the class AZ, BZ, CZ. To this end, to solve this subproblem, we built an expert system based on the Mamdani fuzzy logic inference algorithm[6] in the Fuzzy Logic Toolbox of the MATLAB computing environment [8].

\section{Conclusions}

The article describes a fuzzy classification method for drug demand using $\mathrm{ABC}$ and $\mathrm{XYZ}$ analysis.

$\mathrm{ABC}$ analysis allows you to sort and group products according to their contribution to sales, while XYZ analysis allows you to sort and group products according to the nature of the demand: how stable it is and how accurately it can be predicted. Their combined combination allows you to classify products into 9 groups.

Rules have been developed, with the help of which you can make a fuzzy classification of goods.

Using this approach to solve the problem of demand forecasting allows taking into account both statistical data and the experience and intuition of the managerial staff of the pharmacy network at various stages of demand forecasting and is flexible in terms of the availability of sufficient information about demand. 
Since, with an increase in the sale of medicines and drugs using this approach, demand moves from the class of dissatisfaction to realized demand.

Due to the fact that drugs have their own specific features, we are conducting further research to improve the expert system in order to determine the desired best amount of demand for unmet and emerging demand.

\section{Conflict of Interest}

No conflict of interest.

\section{Bibliography}

1. Особенности спроса на фармацевтическом рынке [Osobennosti sprosa na farmatsevticheskom rynke]. http://www.alppp. ru/law/informacija-i-informatizacija/44/statja--osobennosti-sprosa-na-farmacevticheskom-rynke.html.(accessed on 23.04.2021).

2. Tichonov EYe. “Методы прогнозирования в условиях рынка [Metody prognozirovaniya v usloviyakh rynka]: uchebnoye posobiye". Nevinnomyssk (2006): 221.

3. "How to Use ABC Analysis for Inventory Management (and the Added Value of XYZ Analysis)". https://www.eazystock.com/ uk/blog-uk/abc-classification-calculation-inventory-management/ (accessed on 23.04.2021).

4. “ABC XYZ Inventory Management”. https://abcsupplychain. com/en/abc-xyz-analyse/ (accessed on 23.04.2021).

5. Zadeh Lotfi A. "Fuzzy Logic, Neural Networks, and Soft Computing". Communications of the ACM 37.3 (1994): 77-84.

6. Aliev RA., et al. "Soft Computing and its Applications in Business and Economics". Springer-Verlag Berlin Heidelberg (2004).

7. Takagi T and Sugeno M. "Fuzzy identification of systems and its applications to modeling and control". IEEE Transactions on Systems, Man and Cybernetics 15 (1985): 116-132.

8. Beale MH., et al. "Neural Network ToolboxTM User's Guide". Natick: The MathWorks, Inc., (2014): 435.
9. Jonas S. "Mathematica Neural Networks, Train and Analyze Neural Networks to fit your Data". Wolfram Research, Inc Illinois, USA (2005): 406.

10. Khaykin S. “Нейронные сети[Neyronnyye seti]: Polnyy kurs: Perevod s angl”. Moskva (2008): 1103.

11. Alekperov RB and Iskanderli IT. "Application of Neural Networks for Segmentation of Catering Services Market Within the Overall System of Consumer Market on the Model of Restaurant Business with the Aim to Advance the Efficiency of Marketing Policy". 13th International Conference on Theory and Application of Fuzzy Systems and Soft Computing - ICAFS-2018. ICAFS 2018. Advances in Intelligent Systems and Computing 896 (2019): 905-913. https://doi. org/10.1007/978-3-030-04164-9_120

12. Alekperov RB and Ibrahimova KA. "Neural Network Modeling and Estimation of the Effectiveness of the Financing Policy Impact on the Socio-Economic Development of the Socio-Educational System". 13th International Conference on Theory and Application of Fuzzy Systems and Soft Computing - ICAFS-2018. ICAFS 2018. Advances in Intelligent Systems and Computing 896 (2019): 754-759. https://doi. org/10.1007/978-3-030-04164-9_99

13. Alekperov RB and Iskandarova IT. "A Method for Forecasting the Demand for Pharmaceutical Products in a Distributed Pharmacy Network Based on an Integrated Approach Using Fuzzy Logic and Neural Networks". In: Kahraman C., Cevik Onar S., Oztaysi B., Sari I., Cebi S., Tolga A. (eds) Intelligent and Fuzzy Techniques: Smart and Innovative Solutions. INFUS 2020. Advances in Intelligent Systems and Computing 1197 (2021): 228-237. https://doi.org/10.1007/978-3-03051156-2_116

\section{Volume 5 Issue 6 June 2021}

(C) All rights are reserved by Ramiz Alekperov. 